\title{
Impact of CPAP therapy on health-related quality of life in elderly patients with apnoea-hypopnea syndrome: a systematic review of randomised clinical trials
}

\section{To Editor:}

Obstructive sleep apnoea (OSA) is a chronic pathology characterised by the presence of repetitive upper airway obstruction during the sleep, the prevalence of which increases with the age [1], and for which continuous positive airway pressure (CPAP) is the treatment of choice [2-4]. However, there have been few studies on diagnosis and management of OSA in elderly people. A qualitative systematic review of randomised clinical trials (RCTs) was conducted to evaluate the impact of CPAP therapy on health-related quality of life (HRQL) in OSA patients (aged $>65$ years), diagnosed by polysomnography or polygraphy and treated with CPAP for at least 3 months $\left(>4 \mathrm{~h} \cdot \mathrm{day}^{-1}\right)$. Studies whose primary outcome did not assess HRQL were excluded. Interventions were categorised according to whether or not they included CPAP treatment. The primary outcome was HRQL based on validated generic or specific questionnaires.

Following quality guidelines for conducting systematic literature reviews [5], research was carried out in November and December 2015; trials were identified in the records of Trip, Scopus, the Cochrane Controlled Trials Register and Medline. Studies published since November 2000 were identified using Medical Subject Headings: "CPAP", "SAHS", "quality of life", "therapeutic effect" and "elderly". The search formula was: "CPAP [AND] OSA [AND] quality life; CPAP [AND] quality life; OSA [AND] quality life". Subsequently, two authors classified the studies independently, taking into account the summary, key words and title of the study. At a second level, two researchers independently determined the eligibility and quality of the studies, and the performed intervention. Disagreements were analysed and resolved by discussion.

We found up to 896 potentially relevant articles; in the first evaluation, 868 of them were rejected, as they did not comply with some of the requirements. In the second evaluation, from these 28 studies, one was ruled out because it was not finished and nine because they were not RCTs with control groups. In the third evaluation, from 18 studies, 16 were ruled out because the average age was $<65$ years. Finally, only two RCTs were included in the review; the main results are shown in table 1.

It must be emphasised that researchers come to the same conclusion despite using different questionnaires. MarTíneZ-García et al. [6] used the Quebec Sleep Questionnaire (QSQ) [8], which is appropriate for OSA patients. In the PREDICT study [7], two general questionnaires and one specific for OSA were used. The general ones were Short-Form 36 (SF-36) [9], validated for OSA patients, and European Quality of Life-5 Dimensions (EQ-5D) $[10,11]$ questionnaire, which does not have enough sensitivity to measure the health of the patient individually, while the specific questionnaire was the Sleep Apnea Quality of Life Index (SAQLI) [12], the only one that takes into account the possible impact of the use of CPAP. MARTínez-GARCía et al. [6] show that the CPAP group improved in every domain of the QSQ test $(\mathrm{p}<0.001$; size of the effect $0.4-0.98)$ and also for the symptoms related to sleep ( $\mathrm{p}<0.001$; size of the effect $0.31-0.91$ ). In the PREDICT study, the HRQL was tested through these questionnaires: EQ-5D, SF-36 and SAQLI. These questionnaires were administered immediately after the polysomnography study, and 3 and 12 months later, in both the control and CPAP groups. The CPAP patients had better outcomes in HRQL measured by the SF-36 and SAQLI, compared to baseline data. In relation to the control group, in the CPAP group, daytime sleepiness was improved at

@ERSpublications

CPAP therapy could have a positive impact on health-related quality of life of elderly patients with OSA http://ow.ly/Qxtf305VNa2

Cite this article as: Serrano Merino J, Pérula de Torres LA, Muñoz Gómez R, et al. Impact of CPAP therapy on health-related quality of life in elderly patients with apnoea-hypopnea syndrome: a systematic review of randomised clinical trials. Eur Respir J 2017; 49: 1601644 [https://doi.org/10.1183/ 13993003.01644-2016]. 
TABLE 1 Results of trials included

Martínez-García et al. [6]

$\geqslant 70$ years of age with OSA

Spain (12 clinical centres)

Randomised multicentre clinical

trial with a blinded design

$$
115 / 109
$$

Participants in CPAP/control groups

Selection criteria

Inclusion

Exclusion

\section{Intervention CPAP/control group}

\section{Mean follow-up months}

Primary end-point

Secondary end-points

\section{Age years mean $\pm s D$}

Men/women

BMI $\mathrm{kg} \cdot \mathrm{m}^{-2} \mathrm{CPAP} /$ control mean $\pm \mathrm{SD}$
Age $\geqslant 70$ years, $A H I \geqslant 30$ events per $h$, current use of CPAP, central sleep apnoea, incapacitating hypersomnia

Severe heart failure, a cardiovascular event in the month prior to the inclusion in the study,

ESS $\geqslant 18$, severe impairment of cognitive.

Treatment with CPAP and health education/health education

3

Neurocognitive battery test, HADS $75 \pm 3.9$

$153(68 \%) / 71(32 \%)$

$33.0 \pm 7.3 / 32.8 \pm 5.1$ Blood pressure measurements
McMiLlan et al. [7]

$\geqslant 65$ years of age with OSA UK (14 clinical centres)

Randomised multicentre clinical trial with a blinded design

$$
140 / 138
$$

Age $\geqslant 65$ years, OSA, AHI $\geqslant 7$ events per $\mathrm{h}, \mathrm{ESS} \geqslant 9, \mathrm{ODI}>4 \%$

CPAP therapy (previous study), $\mathrm{SpO}_{2}$ (vigil) $<90 \%, \mathrm{FEV}_{1} / \mathrm{FVC}<60 \%$, being a professiona driver, reporting sleepiness while driving, shift work

Treatment with CPAP and health education/health education 12

ESS, cost-effectiveness SAQLI, OSLER, EQ-5D, SF-36, cardiovascular risk factor $71.1 \pm 4.6$

$229(83.38 \%) / 49(16.62 \%)$

\begin{tabular}{|c|c|c|c|c|c|c|}
\hline & \multicolumn{3}{|c|}{ QSQ } & \multicolumn{3}{|c|}{ SAQLI total } \\
\hline & Hypersomnolence & Diurna & nptoms & & ths & 12 months \\
\hline \multirow{2}{*}{$\begin{array}{l}\text { Treatment effect }(95 \% \mathrm{Cl}) \\
\text { p-value }\end{array}$} & $-0.612(-0.894--0.331)$ & \multicolumn{2}{|c|}{$\begin{array}{c}-0.778(-1.049--0.506) \\
<0.001\end{array}$} & \multicolumn{2}{|c|}{$\begin{array}{c}0.3(0.1-0.5) \\
0.005\end{array}$} & $0.4(0.2-0.6)$ \\
\hline & Nocturnal symptoms & Emotions & Social interaction & & & \\
\hline $\begin{array}{l}\text { Treatment effect }(95 \% \mathrm{Cl}) \\
\text { p-value }\end{array}$ & $\begin{array}{c}-0.958(-1.249--0.668) \\
<0.001\end{array}$ & $\begin{array}{c}-0.597(-0.864--0.331) \\
<0.001\end{array}$ & $\begin{array}{c}-0.546(-0.833--0.259) \\
<0.001\end{array}$ & & & \\
\hline ESS mean士sD & Baseline & \multicolumn{2}{|c|}{3 months } & Baseline & 3 months & 12 months \\
\hline CPAP group & $9.56 \pm 4.0$ & \multicolumn{2}{|c|}{$5.94 \pm 3.41$} & $11.6 \pm 3.4$ & $7.7 \pm 0.4$ & $5.7 \pm 1.2$ \\
\hline Control group & $9.33 \pm 3.62$ & \multicolumn{2}{|c|}{$9.22 \pm 3.99$} & $11.6 \pm 3.4$ & $9.8 \pm 0.4$ & $9.1 \pm 1.2$ \\
\hline p-value & $>0.05$ & \multicolumn{2}{|c|}{$<0.001$} & $>0.05$ & 0.002 & 0.002 \\
\hline
\end{tabular}

$33.9 \pm 5.7 / 33.6 \pm 6.4$ 
3 months $(\mathrm{p}=0.002)$ and at 12 months $(\mathrm{p}<0.001)$. The average increment of quality-adjusted life years obtained in the EQ-D5 for CPAP group, in relation to control group, was 0.01 (95\% CI 0.63-0.71, $\mathrm{p}=0.787$ ).

The two RCTs show that CPAP therapy increases HRQL; this improvement is significant in the patient's energy or vitality, and in the diurnal symptoms. The positive impact of CPAP on HRQL in elderly patients is an important finding that sheds light on the lack of scientific evidence on the effect of this therapy [13]. However, the lack of an analysis correlating the impact of CPAP on HRQL and the age of subjects makes it difficult to define the age at which the CPAP can make a significant improvement in quality of life. Moreover, the authors did not study the influence of sex on this therapy, since the role of CPAP in women may be different [14].

The study by MarTínez-García et al. [6] showed the highest percentage of adherence to CPAP therapy (69.6\%, as opposed to $35.0 \%$ in the PREDICT study). However, the MARTínez-GARCía et al. [6] study lasted 3 months, versus 12 months for the PREDICT study, and this could explain this divergence. In the selected studies, the diagnosis of OSA was not performed in all patients by polysomnography, so the quality of sleep and HRQL could not be related.

In conclusion, the results of the two clinical trials included in the review underline that CPAP could have a positive impact in patients older than 65 years, particularly on nocturnal and diurnal symptoms, and on HRQL. However, the small number of trials prevents us from reaching conclusions. More studies on the treatment effect of CPAP on HRQL in patients older than 65 years with OSA are needed.

Jesús Serrano Merino, ${ }^{1,2}$, Luis A. Pérula de Torres ${ }^{2,3}$, Rafaela Muñoz Gómez ${ }^{4}$, Ana Roldán Villalobos ${ }^{2,3}$, M. Nuria Feu Collado ${ }^{1}$, Roger Ruiz-Moral ${ }^{2,5}$, Bernabe Jurado-Gámez ${ }^{1,2,6}$ and the Collaborative Group CVCPAP Study

${ }^{1}$ Sleep Unit, Respiratory Dept, University Hospital Reina Sofia, Córdoba, Spain. ${ }^{2}$ Instituto Maimónides de Investigación Biomédica de Córdoba (IMIBIC), Hospital Universitario Reina Sofía, Universidad de Córdoba, Córdoba, Spain. ${ }^{3}$ Unidad Docente de Medicina Familiar y Comunitaria, Health District of Córdoba and Guadalquivir, Córdoba, Spain. ${ }^{4} \mathrm{UGC}$ Sector Sur, Health District of Córdoba and Guadalquivir, Córdoba, Spain. ${ }^{5}$ Faculty of Medicine, University of Francisco de Vitoria, Madrid, Spain. ${ }^{6}$ Faculty of Medicine, University of Córdoba, Córdoba, Spain.

Correspondence: Jesús Serrano Merino, University Hospital Reina Sofia, c/ Serbal 39, 14012-Córdoba, Spain.

E-mail: jesussleep@hotmail.com

Received: June 292016 | Accepted after revision: Oct 042016

Support statement: This article has been supported by grants of the Public Andalusian Foundation of Process and Health for financing projects in Biomedical Investigation and Sciences of Health in Andalusia (PI-0281-2014), and to the call for the fulfilment of projects in investigation and innovation in the Primary Attention of Andalusian Service of Health (PI-0025-2015).

Conflict of interest: None declared.

Acknowledgements: We thank Raisa Serrano Muñoz (Universidad de Córdoba, Córdoba, Spain) for the translation of this manuscript.

\section{References}

1 Durán J, Esnaola S, Rubio R, et al. Obstructive sleep apnoea-hypopnoea in the elderly. A population-based study in the general population aged 71-100. Eur Respir J 2000; 16: Suppl. 31, 167 S.

2 Giles TL, Lasserson TJ, Smith BH, et al. Continuous positive airways pressure for obstructive sleep apnoea in adults. Cochrane Database Sys Rev 2006; 3: CD001106.

3 Montserrat JM, Amilibia J, Barbé E, et al. Treatment of sleep apnea-hypoapnea syndrome. Arch Bronconeumol 1998; 34: 204-206.

4 Grupo Español de Sueño. Consenso Nacional sobre Síndrome de apnea-hipopnea del sueño. Arch Bronconeumol 2005; 41: Suppl. 4, 7-10.

5 Urrútia G, Bonfill X. PRISMA declaration: a proposal to improve the publication of systemic reviews and meta-analyses. Med Clin (Barc) 2010; 135: 507-511.

6 Martínez-García MA, Chiner E, Hernández L, et al. Obstructive sleep apnoea in the elderly: role of continuous positive airway pressure treatment. Eur Respir J 2015; 46: 142-151.

7 McMillan A, Bratton DJ, Faria R, et al. Continuous positive airway pressure in older people with obstructive sleep apnoea syndrome (PREDICT): a 12-month, multicentre, randomised trial. Lancet Respir Med 2014; 2: 804-812.

8 Catalán P, Martínez A, Herrejón A, et al. Internal consistency and validity of the Spanish version of the "Quebec Sleep Questionnaire” quality-of-life questionnaire for obstructive sleep apnea. Arch Bronconeumol 2012; 48: 107-113.

9 Brazier J, Roberts J, Deverill M. The estimation of a preference-based measure of health from the SF-36. J Health Econ 2002; 21: 271-292.

10 Brooks R. EuroQol: the current state of play. Health Policy 1996; 37: 53-72.

11 EuroQol Group. EuroQol - a new facility for the measurement of health-related quality of life. Health Policy 1990; 16: $199-208$

12 Flemons WW, Reimer MA. Development of a disease-specific health-related quality of life questionnaire for sleep apnea. Am J Respir Crit Care Med 1998; 158: 494-503. 
13 Weaver TE, Chasens ER. Continuous positive airway pressure treatment for sleep apnea in older adults. Sleep Med Rev 2007; 11: 99-111.

14 Campos-Rodriguez F, Queipo-Corona C, Carmona-Bernal C, et al. Continuous positive airway pressure improves quality of life in women with OSA. A randomized-controlled trial. Am J Respir Crit Care Med 2016; 194: $1286-1294$.

Copyright (CERS 2017 